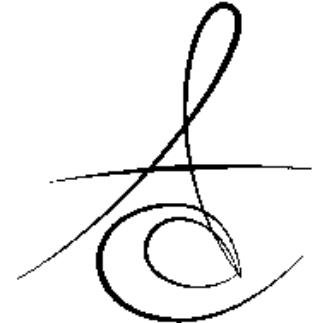

Makale Kodu/Article code: 2031

Makale Gönderilme tarihi: 26.12 .2014

Kabul Tarihi: 18.05.2015

\section{DİŞ HEKİMLİĞİ ÖĞRENCİLERİNİN RENK ÖLÇÜM BAŞARILARININ DEĞERLENDİRİLMESİ}

\section{EVALUATION OF THE SHADE MATCHING SUCCESSES OF DENTAL STUDENTS}

\author{
Dr. Oğuz BİLGíç̧*
}

\section{ÖZET}

Amaç: Diş hekimliğinde kullanılan renk ölçüm metodlarının ve renk ölçüm cihazlarının tutarlılığının in vivo karşılaştırıması, diş hekimliği öğrencilerinin renk seçme becerilerini renk ölçüm cihazları ile karşılaştırarak ne kadar doğru renk seçimi yaptıklarını ve hangi yöntem ile en başarılı renk seçimi yaptıklarını değerlendirmektir.

Metod ve Materyal: Çalışma in vivo koşullarda ve 70 kişilik bir çalışma grubu oluşturarak yapılmıştır. Diş hekimliği son sınıf öğrencilerinden oluşan üç kişilik grup Vita Easyshade $\AA$, Dentsply Shadestar,Vita 3Dmaster renk skalası ve Vitapan klasik renk skalalarını kullanarak, sağ maksiller kesici dişten Vita sisteminde 3 farklı yöntemle, 3D-Master sisteminde de 3 farklı yöntemle renk ölçümleri yapmıştır. Her sistemde yapılan ölçümler kendi aralarında T-testi kullanılarak karşılaştırılmış ve tutarlılıkları belirlenmiştir $(p<0,05)$.

Bulgular: Vita Easyshade $\AA$ ile Dentsply Shadestar'dan elde edilen veriler Vita sistemine göre istatistiksel olarak anlamlı bulunurken ( $a=0.009)$, 3DMaster sisteminde yapılan eşleştirme kabul edilir sınırın dışında istatistiksel olarak anlamsız sonuç vermiştir ( $a=0.924)$. Öğrencilerin yaptığı ölçümlerde ise sadece vita skalasıyla yapılan ölçüm ile Vita Easyshade $\circledR$ arasındaki sonuçlar istatistiksel olarak anlamlı bulunurken ( $a=0.047$ ), diğer bütün ölçümlerde istatistiksel olarak anlamsız sonuçlar elde edilmiştir.

Sonuç: Diş hekimliğinde renk seçimi klinik tecrübe ile doğru orantılıdır. Diş Hekimliği öğrencilerinin renk seçiminde klasik Vita skalası veya klasik Vita renk skalasına ait değerlere göre ayarlanmış renk ölçüm cihazlarını kullanması renk ölçüm başarısını beraberinde getirecektir.

Anahtar Kelime: Renk ölçüm aletleri, renk ölçüm metotları, spektrofotometre, renk seçimi

\section{ABSTRACT}

Aim: The aims of this study were to compare the dental shade matching methods and evaluate their consistency, the shade matching ability of dental students with the help of colorimeters and to find the best way of shade matching for them

Methods and Materials: Study has been made in in vivo conditions with 70 participants. A group of 3 dental student has made their observations with Vita Easyshade $\Re$, Dentsply Shadestar, Vita 3D-master and Vita Classical Scales on the first right maxillary central tooth. Three different data collected on Vita system and three different data collected on 3D-Master system and for each group, all these data were compared separately with T-test and their consistency was evaluated ( $p<0,05)$.

Results: The values obtained from the comparison of Vita Easyshade ${ }^{\circ}$ and Dentsply Shademaster colorimeters were statistically significant in Vita system $(a=0.009)$ but insignificant in 3D- master system $(a=0.924)$. The values obtained from the comparison of Vita Easyshade $\AA$ and Vitapan classical scale were statistically significant ( $a=0.047)$.

Conclusion: Shade matching is proportional to the clinical experience in dentistry. To use Vita Classic scale or Vita Easyshade ${ }^{\circledR}$ and Dentsply Shademaster colorimeters in Vita system will bring color measuring success for dental students.

Keywords: Dental shade devices, shade matching methods, spectrophotometer, color matching.

\footnotetext{
* Serbest Diş hekimi,l

** Marmara Üniversitesi Dişhekimliği Fakültesi, Protetik Diş Tedavisi Anablim Dalı
} 


\section{GİRİş}

Diş hekimliğinde renk seçimi hastayı estetik açıdan tatmin etmek ve doğal bir görünüm sağlamak açısından çok önemlidir. İnsan gözü rengi açık, net ve devamlı bir şekilde algılayamadığı için renk belirlemede bireysel farklılıklar gözlenebilir.

Doğal dişlerle uyumlu renkte restorasyon yapabilmek için diş rengini doğru tanımlayabilmek önemlidir. Renk seçimi klinisyen için zor ve titizlikle yapılması gereken bir işlemdir. Renk seçimi subjektif olduğu için her zaman tutarlı sonuçlar almak zordur. Diş hekimleri arasında farklılıklar olduğu gibi, aynı diş hekiminin farklı zamanlarda aynı rengi farklı şekilde algıladığı da bildirilmiştir ${ }^{1}$. Rengin algılanmasına birçok değişken etki eder. Işık kaynağı, hastanın kıyafeti ve makyajı, renk seçiminin yapılacağı odanın rengi ve dişin yüzey özellikleri rengin algılanmasına etki eden faktörlerdir ${ }^{2-4}$

Endüstride materyallerin renk seçiminde kullanılan spektrofotometre ve kolorimetreler mevcuttur. Spektrofotometreler doğal çekilmiş ve canlı dişlerin görünür spektrumunu ölçerler. Kolorimetreler renk filtrelerine sahiptirler ve bu filtreler insan gözünü taklit ederler. Bu cihazlar rengi CIE Lab değerlerinde ölçmek için tasarlamışlardır. İn vitro ve in vivo yapılan diş rengi ile ilgili çalışmaların büyük çoğunluğunda kolorimetreler kullanılmaktadır. Kolorimetreler renk ölçümünde spektrofotometrelerle karşılaştırılmışlardır ve elde edilen sonuçlar güvenilir ve başarılı bulunmuştur $^{5-9}$. Genel olarak kolorimetreler in vivo ve in vitro çalışmalarda doğal diş renk ölçümlerinde tekrarlanabilirlik açısından başarılı sonuçlar göstermişlerdir.

Kolorimetreler ve insan gözünün renk analizi bağlantılarının incelendiği çalışmaların sonuçları henüz bir yargıya varmak için yeterli değildir. Bazı araştırıcılar aletsel ölçümler ve insan ölçümleri arasında belirgin bağlantı bulmuşken bazı araştırıcıların bulduğu sonuçlar belirgin değildir. Kolorimetrelerin kullanımında birtakım zorluklar ve dezavantajlar vardır. Bu cihazlar düz yüzeylerde ölçümler için tasarlanmışlardır ${ }^{7}$. Dişler çoğunlukla düz yüzeylere sahip değillerdir ve yüzey düzensizlikleri gösterebilirler. Dar açıklığa sahip cihazlarda edge-loss şeklinde tabir edilen, renk ölçümü yapılan nesneden yansıyan ışığın cihaza tam olarak dönememesi şeklinde açıklanan problemler gözlenir.

Çalışmamızın amacı, diş hekimliği öğrencilerinin renk seçme becerilerini renk ölçüm cihazları ile karşılaştırarak ne kadar doğru renk seçimi yaptıklarını ve hangi yöntem ile en başarılı renk seçimi yaptıkları konusunda bir sonuca varmaktır. Ayrıca, 18-19 yas ortalamasına sahip bireylerin sahip oldukları diş rengini tespit edebilmek ve çalışmamızda test edilen renk ölçüm cihazlarından elde edilen verileri karşılaştırarak, ilgili cihazların tutarlılığını ölçmektir. Çalışmanın hipotezi, test edilen renk ölçüm aletleri ve renk skalaları ile diş rengi seçim sonucunun aynı olacağıdır.

\section{GEREÇ VE YÖNTEM}

Çalışma grubu, M.Ü. Dişhekimliği Fakültesi 1. Sınıf öğrencilerinden oluşturulmuştur. Öğrencilere, çalışma hakkında bilgi verilmiş ve çalışmaya katılıp katılmak istemedikleri sorulmuştur. 37 kız ve 33 erkek öğrenci çalışmaya katılmıştır. Kız ve erkek öğrencilerin yaş ortalaması 18,5 'dur. Çalışmada diş renklerini belirlemek için; Vita Easyshade Spectrophotometer (VITA Zahnfabrik H.Rauter GmbH \& Co.KG, Bad Säckingen,Germany), Dentsply Shadestar (DeguDent $\mathrm{GmbH}$, Hanau, Germany), Vitapan klasik renk skalası (VITA Zahnfabrik H.Rauter GmbH \& Co.KG, Bad Säckingen,Germany), ve Vita 3D-Master renk skalası (VITA Zahnfabrik H.Rauter GmbH \& Co.KG, Bad Säckingen,Germany), kullanılmıştır. Diş renginin belirlenmesi amacı ile üç grup oluşturulmuştur. Tüm gruplardaki ölçümler, M.Ü. Dişhekimliği Fakültesi'nde 5. Sınıfta okuyan üç öğrenci tarafından yapılmıştır. Renk belirleme çalışmasında her öğrenci değişik bir materyal ile ve diğer öğrencinin belirlediği renkten habersiz bir şekilde renk seçimini yapmıştır. Birinci gruptaki öğrenci Vitapan klasik renk skalası (VITA Zahnfabrik H.Rauter GmbH \& Co.KG, Bad Säckingen,Germany), ve Vita 3D-Master renk skalası (VITA Zahnfabrik H.Rauter GmbH \& Co.KG, Bad Säckingen,Germany), ile diş rengini belirlemiştir. İkinci gruptaki öğrenci Vita Easyshade Spectrophotometer (VITA Zahnfabrik H.Rauter GmbH \& Co.KG, Bad Säckingen,Germany) renk ölçüm aleti ile ve üçüncü gruptaki öğrenci de Dentsply Shadestar (DeguDent $\mathrm{GmbH}$, Hanau, Germany) renk ölçüm aleti ile deneklerin diş renklerini belirlemişlerdir. Bütün renk ölçümleri maksiller sağ birinci kesici dişten yapılmıştır. Çalışma grubundaki bireylerin bu dişlerinde restorasyon veya herhangi bir faktörden dolayı renk değişimi olmamasına dikkat edilmiştir. Göz yorgunluğu olmaması ve ölçümlerin öğle saatinde 
yapılmasına dikkat edildiği için çalışmalar bir hafta ara ile toplam iki günde tamamlanmışıır.

Renk ölçüm cihazları hem klasik Vita skalasına, hem de 3D-Master skalasına ait değerler verir. Renk ölçüm cihazları ile yapılan ölçümlerde alet, sağ maksiller santral kesici dişinin orta üçlüsüne konulmuş renk belirlenmiş, gözlemcinin 3 kez yapmış olduğu belirlemeden sonra çıkan en az iki uyumlu sonuç o gözlemcinin ilgili örneğe ait elde ettiği renk olarak yazıımıştır. Ölçümler öncesi renk ölçüm cihazlarının özel kalibrasyon aleti ile kalibrasyonu yapıımıştır. 70 adet 1. Sınıf öğrencisinden, birinci grupta 420 ölçüm ikinci gruptan 210 ve üçüncü grupta 210 ölçüm olmak üzere toplam 840 ölçüm yapılmıştır.

Çalışmada elde edilen bulgular değerlendirilirken, istatistiksel analizler için SPSS (Statistical Package for Social Sciences) Windows 17.0 programı kullanıımışır. Çalışma verileri değerlendirilirken tanımlayıcı istatistiksel metotlardan (Frekans, Yüzde, Ortalama, Standart sapma) yararlanıımışır. Sonuçlar \% 95 güven aralı̆ında, anlamlılık $p<0,05$ düzeyinde değerlendirilmiştir. Verilerin istatistiksel karşılaştırılmasında $T$ testi kullanılmışır.

\section{BULGULAR}

Çalışmamızda 3D-Master renk sistemi için 3 adet (3DMaster skala, Vita Easyshade Spektrofotometre, Dentsply Shadestar ) ve Vita renk sistemi için 3 adet ( Vita skala, Vita Easyshade Spektrofotometre, Dentsply Shadestar) olmak üzere toplam 6 adet sonuç tablosu elde edilmiştir (Şekil 1-6).

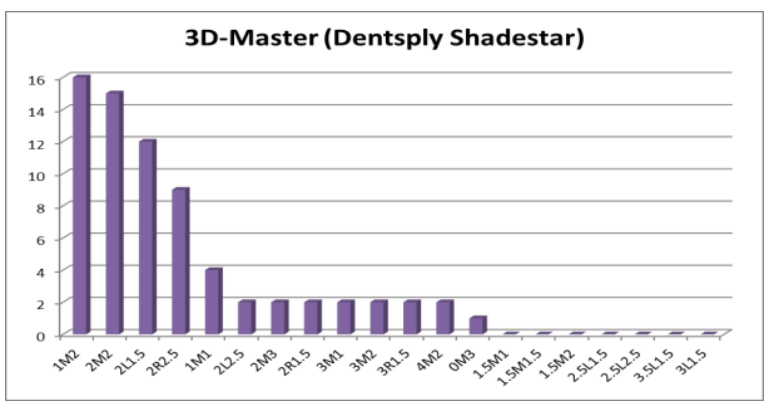

Şekil 1 Dentsply Shadestar ile elde edilen 13 rengin dağılımı

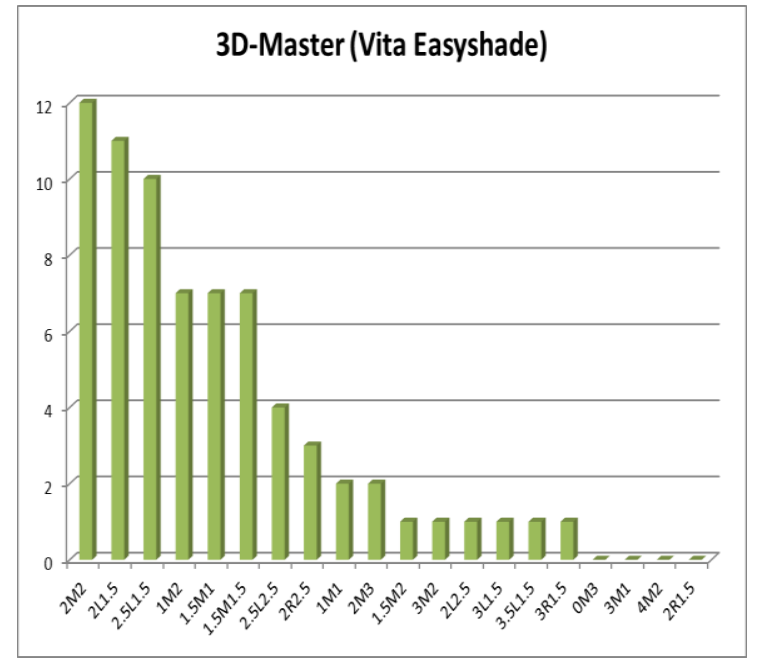

Şekil 2 Vita Easyshade spektrofotometre ile elde edilen 16 rengin dağılımı

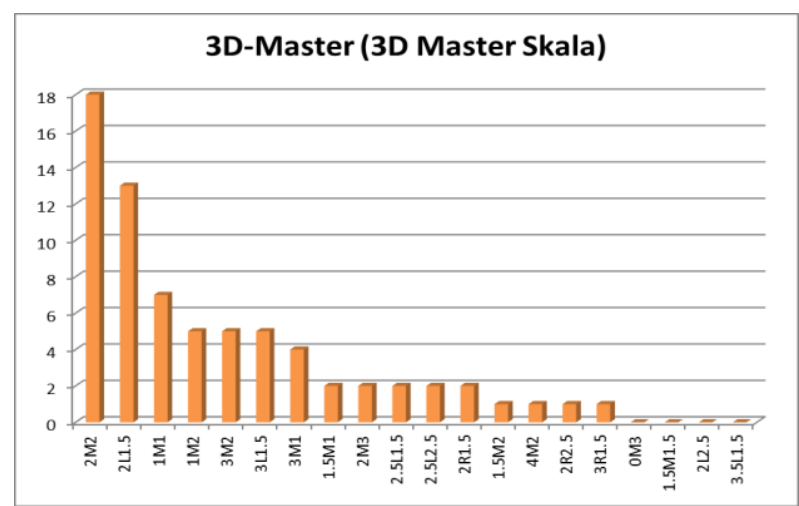

Şekil 3. 3D-master skalası ile elde edilen 16 rengin dağııımı

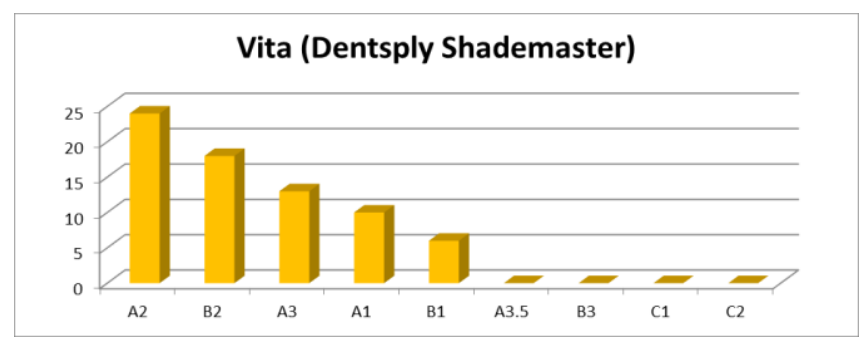

Şekil 4 Dentsply Shademaster ile elde edilen 5 rengin dağılımı 


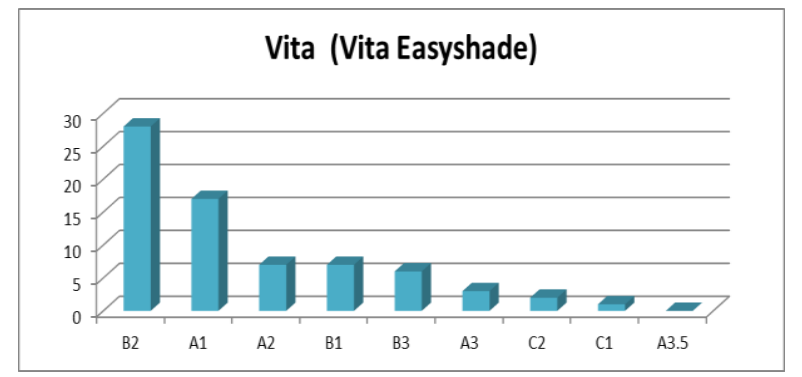

Şekil 5 . Vita Easyshade ile elde edilen 8 rengin dağılımı

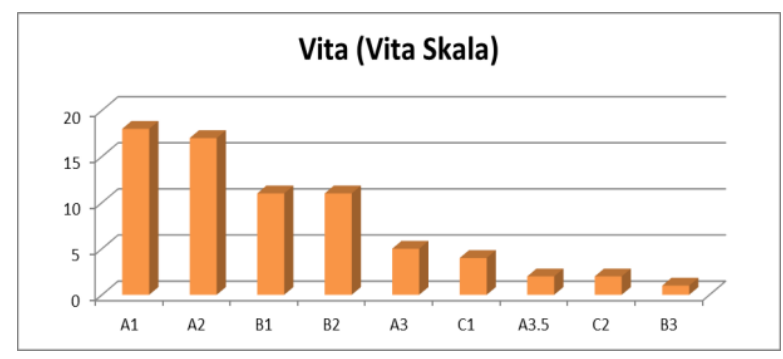

Şekil 6 Vita skalası ile elde edilen 9 rengin dağılımı
Dentsply Shademaster ile yapılan ölçümlerde (Şekil 4) 5 renk ölçülmüştür. Bu ölçümlerde \%33.80 oranı ile $(n=24) A 2$ rengi en fazla çıkan renk olmuştur. B2 rengi de \%25.35 oranı ile $(n=18)$ gözlemlenmiştir

Vita Easyshade ile yapılan ölçümlerde (Şekil 5) 8 farklı renk ölçülmüş olup en çok gözlemlenen renk $\% 39.44(n=28)$ B2 rengi olmuştur. A1 rengi ise $\% 23.94$ oranı ile $(n=17)$ gözlemlenmiştir.

Vita skalası ile yapılan ölçümlerde (Şekil 6) ise 9 farklı renk gözlemlenmiştir. A1 rengi \%25.35 oranı ile $(n=18)$ en çok ölçülen renk olmuştur. $A 2$ rengi ise \%23,94 oranı ile $(n=17)$ gözlemlenmiştir.

Yapılan çalışmaların istatistiksel karşılaştırılması ve renk seçim yöntemlerinin güvenilirliği için $\mathrm{T}$ testi kullanılmıştır. (Tablo 1), p anlamlılık düzeyi \%5 olarak belirlenmiştir.

Vita Easyshade ile Dentsply Shadestar arasındakı ölçümler Vita sistemine göre istatistiksel olarak anlamlı farklılığa rastlandı ( $a=0.009)$, 3D-Master sisteminde yapılan eşleştirme kabul edilir sınırın dışında istatistiksel olarak anlamlı değildir ( $a=0.924)$.

Tablo 1. T testi

\begin{tabular}{|l|l|l|l|l|l|l|}
\hline & $\begin{array}{l}\text { 3D } \\
\text { M(Dentsply- } \\
\text { Easyshade) }\end{array}$ & $\begin{array}{l}\text { 3D } \\
\text { M(Dentsply- } \\
\text { Scala) }\end{array}$ & $\begin{array}{l}\text { 3D } \\
\text { M(Easyshade- } \\
\text { Scala) }\end{array}$ & $\begin{array}{l}\text { Vita (Dentsply- } \\
\text { Easyshade) }\end{array}$ & $\begin{array}{l}\text { Vita } \\
\text { (Dentsply- } \\
\text { Scala) }\end{array}$ & $\begin{array}{l}\text { Vita } \\
\text { (Easyshade- } \\
\text { Scala) }\end{array}$ \\
\hline p değeri & 0,924 & 0,938 & 0,839 & 0,009 & 0,473 & 0,047 \\
\hline
\end{tabular}

$p<0,05$

Çalışma grubunda 3D-Master sistemine göre yapılan ölçümlerde toplam 20 renk gözlemlenmiştir.

Dentsply Shadestar ile yapılan ölçümde (Şekil 1) çalışma grubundan 13 farklı renk ölçülmüştür. Seçilen topluluktaki en fazla çıkan sonuç $\% 22,56$ oranı ile $(n=16) 1 M 2$ rengi olmuştur. Bu ölçüme en yakın olan sonuç \%21.13 $(n=15)$ ile 2M2 rengidir.

Vita Easyshade spektrofotometre ile yapılan ölçümlerde ise (Şekil 2) 16 farklı renk gözlemlenmiştir. Seçilen topluluktaki en fazla çıkan sonuç \%16.9 oranı ile $(n=12) 2 M 2$ rengi olmuştur. Bu ölçüme en yakın sonuç \%15.49 ile 2L1.5 $(n=11)$ rengidir.

3D-master skalası ile yapılan ölçümlerde (Şekil 3) gözlemci 16 farklı renk belirlemiştir. Skala ile yapılan gözlemde en çok çıkan sonuç \%25.12 ile $(n=18) 2 M 2$ olmuştur ikinci en fazla gözlemlenen renk ise $\% 18,31$ ile $(n=11)$ 2L1.5 olarak belirlenmiştir.

Vita sistemine göre yapılan ölçümlerde toplam 9 renk gözlemlenmiştir.
Vita skalasıyla yapılan ölçümler ile Vita Easyshade arasındaki sonuçlar istatistiksel olarak anlamlı bulundu( $a=0.047)$, diğer ölçümler de istatistiksel olarak anlamlı sonuçl elde edilmedir.

Test edilenrenk ölçüm cihazları ile Vita sistemi ile uyumlu sonuçlar elde edilirken, 3D-Master sistemi ile yapılan ölçümlerde yeterli eşleme eide edilmedi. Öğrencilerin Vita renk skalası kullanarak elde ettiği sonuçların renk ölçüm cihazları ile uyumlu olduğu, 3DMaster skalası kullana- rak elde edilen sonuçların renk ölçüm cihazlarının sonuçları ile uyumsuz olduğu gözlemlenmiştir.

\section{TARTIŞMA}

Çalışmamızın hipotezi doğrulanmamıştır; test edilen renk ölçüm aletleri ve renk skalaları ile aynı sonuçlar alınmamıştır. Araştırmamızda renk seçimlerinin hepsini diş hekimliği son sınıf öğrencileri 
yapmıştır. Bu öğrenci grubu daha önce sadece Vita skalası ile ölçüm yapmışlardır ve diğer ölçüm yöntemleri hakkında tecrübe sahibi değillerdir. Dagg ve ark. $^{10}$ çalışmalarında tecrübenin renk belirleme üzerine etkisini incelemişlerdir. Çalışma sonuçlarına göre gözlemcinin tecrübesinin renk belirleme için önemli bir etken olduğu belirtilmiştir. 10 tecrübeli diş hekimi ve 10 tecrübesiz diş hekimliği öğrencisinin gözlemci olarak katıldığı çalışmada tecrübeli hekimlerin daha başarılı renk seçtikleri belirtilmiştir. Hammad ${ }^{11}$ çalışmasında 10 protetik diş tedavisi uzmanı ve 10 pratisyen diş hekiminin 20 hasta üzerinde 1.keser dişlerden 2 farklı skala kullanarak yaptıkları renk ölçümlerinin tekrarlanabilirliklerini karşılaştırmıştır. Protez uzmanlarının bizim çalışmamızda da kullanılan klasik Vita renk skalası ile yaptıkları ölçümlerin pratisyen hekimlere oranla daha başarılı olduğu gözlemlenmiştir. Mc Maugh ve ark. ${ }^{12}$ pratisyen diş hekimleri ile branş diş hekimleri arasında renk tonu algılama yeteneği bakımından fark olmadığını ancak; birinci sınıf öğrencileri ile branş diş hekimleri arasında istatistiksel olarak anlamlı fark olduğunu rapor etmişler ve branş diş hekimlerinin renk seçiminde zamanla tecrübe kazandıklarını belirtmişlerdir.

Literatürde renk seçiminde tecrübenin önemli rolü olmadığını savunan görüşler de mevcuttur. Davidson ve Myslinski ${ }^{13}$ protez uzmanları ile protez asistanları arasında renk algılama açısından istatistiksel olarak önemli bir fark bulamadıklarını ve tecrübenin bireylerde renk seçimini geliştirmediğini öne sürmüşlerdir. Yapılan başka bir araştırmada 10 yıldan az ve 10 yıldan fazla çalışan diş hekimleri arasında renk seçme yeteneği açısından fark olmadığını ve tecrübenin renk seçme yeteneğini arttırmadığını bildirmişlerdir ${ }^{14}$. Özdoğan ve ark. ${ }^{15}$ da çalışmalarında protetik diş tedavisi doktora öğrencileri ve 1 . sınıf lisans öğrencileri arasında renk algılama açısından anlamlı farklıık bulamamışlardır. Bizim çalışmamızda öğrenciler daha önceden tecrübeli olduğu Klasik Vita skalasında başarılı sonuçlar elde ederken, 3D-Master skala da başarısız sonuç elde etmiştir. Çalışmamızın sonuçlarına göre tecrübenin başarıyı arttırdığını söyleyebiliriz.

Renk ölçüm cihazlarının ölçümler esnasında yatay ve dikey yönde hareketsizliğinin sağlanması başarılı sonuçlar için tavsiye edilmiştir ${ }^{16,17}$. Buna bağlı kalınarak renk ölçüm cihazının her iki düzlemde hareketsizliğini sağlayan bir sabitleyici aygıt üretilmiş ve in vitro ölçümlerin standardizasyonu sağlanmıştır. $\mathrm{Li}^{18} 2003$ yılında yaptığı çalışmasında in vivo ölçümlerde ise sabitleyicilerin kullanımlarının zor olduğunu belirtmiştir. Çalışmamızda, renk ölçüm aletleri çalışma grubunu oluşturan bireylerin maksiller santral kesici dişlerinin orta üçlüsüne konularak renk belirlenmiştir. Bu bölge ilgili dişin en düz yüzeyini oluşturmaktadır. Renk ölçüm cihazlarının renk ölçümü yapılırken sabit olmasına dikkat edilmiştir. Çalışmamızda, renk ölçüm cihazlarının farklı öğrenciler tarafından kullanılması, dişe yaklaştııılan yüzeylerdeki minimal mine düzensizlikleri de renklerin farklı belirlenmesine neden olmuş olabilir.

Lath ve ark. ${ }^{19}$ çalışmalarında Vita-3D Master skalası üzerindeki renkleri 85 renk eğitimi almamış gözlemciden beyazlıklarına göre sıralamasını istemişlerdir. Aynı renkleri spektrofotometreden alınan beyazlık değerleri ve üreticinin beyazlık sıralaması ve gözlemci sıralaması arasında özellikle açık renklere doğru gidildikçe kuvvetli bir ilişki gözlemlenmişlerdir. Koyu renklere doğru gidildikçe aletsel ve görsel ölçüm sonuçları, üretici dizilimine göre farklılıklar göstermişlerdir. Bizim ölçüm sonuçlarımızda da renk değeri (value) yüksek olan renklerin tespitinde görsel olarak renk değeri (value) düşük olan renklerin tespitinden daha başarılı sonuçlar vermişlerdir. Bu bulgumuzun nedeni olarak renk değerinin azalmasına bağlı olarak renk yoğunluğunun artmasının renk ayrımını güçleştirdiğini söyleyebiliriz.

Vita Easyshade, klasik vita skalasında ve 3DMaster sistemi değerlerini verdiği her iki ölçümde de Dentsply Shadestar'dan daha fazla renk ölçmüştür. Vita Easyshade, Klasik vita sistemine göre 8 farklı renk, 3D-Master sistemine göre de 15 farklı renk belirlerken, Dentsply Shadestar Klasik vita sistemine göre 5 farklı renk, 3D-Master sistemine göre de 12 farklı renk ölçmüştür. Öğrencilerin yaptığı ölçümlerde ise sadece vita skalasıyla yapılan ölçüm ile Vita Easyshade arasındaki sonuçlar istatistiksel olarak anlamlı bulunurken ( $a=0.047)$, diğer bütün ölçümlerde istatistiksel olarak anlamlı olmayan sonuçlar elde edilmiştir. Çalışmamızdan elde edilen sonuçlara göre, diş hekimliği son sınıf öğrencilerinin klasik vita skalası ile belirlediği renkler Vita Easyshade renk ölçüm cihazı ile uyumludur. 


\section{SONUÇ}

Öğrenciler renk seçiminde tecrübeli oldukları klasik vita sisteminde daha başarılı sonuçlar almışlardır. Bu sonuç bize renk seçiminde tecrübenin etkili olduğunu göstermektedir. 3D-Master sisteminde tecrübe kazanıldıkça daha başarılı olunabileceği düşünülse de, 3D-Master skalasında ki 29 farklı rengin, 16 renk içeren klasik vita skalasına göre seçimi daha çok zorlaştırdığı düşünülmektedir.

2 farklı cihaz ile yaptığımız ölçümlerdeki sonuçlar bize bu cihazların klasik vita siteminde güvenilir olduklarını göstermiştir fakat 3D-Master sisteminde hem renk ölçüm cihazlarının tutarsızlığı hem de skala ile yapılan ölçümlerin cihazlarla uyuşmaması, bu sistemde renk ölçümünün pratik olmadığını ve hekimlerin pratiklerinin arttırması gerektiğini düşündürmektedir.

\section{KAYNAKLAR}

1. Culpepper WD. A comparative study of shadematching procedures. J Prosthet Dent 1970;24:166-73.

2. Sorenson JA, Torres TJ. Improved color matching of metal-ceramic restorations. Part 1: A systematic method for shade determination. J Prosthet Dent 1987; 58:133-9.

3. Fondriest J. Shade: Matching in Restorative Dentistry. The Science and Strategies. Int J Periodontics Restorative Dent 2003;23:467-79.

4. Raptis, NV, Michalakis, KX, Hirayama H. Optical behaviour of current ceramic systems. Int J Periodontics Restorative Dent 2006;26:31-41.

5. O'Brien WJ, Heimerdinger $H$, Boenke KM, Linger JB, Groh CL. Color Distrubution of three regions of extracted human teeth. Dent Mater 1997;13:17985.

6. Johnston WM, Kao EC. Assessment of appearance match by visual observation and clinical colorimetry. J Dent Res 1989;68:599-602.

7. van der Burgt TP, ten Bosch JJ, Barsboom PC, Kartsmit WJ. A comparison of new and conventional methods for quantification of tooth color. J Prosthet Dent 1990;63:155-62.

8. Goldstein GR, Schmitt GW. Repeatability of a specially designed intraoral colorimeter. J. Prosthet Dent 1993;69:616-9.
9. Dogan A, Yüzügüllü B. Renk seçiminde güncel teknolojik gelişmeler. Atatürk Üniv. Diş. Hek. Fak. Derg. 2011; Supp. 4:65-72.

10. Dagg H, O'Connell B, Claffey, N, Byrne D. The influence of some different factors on the accuracy of shade selection. J Oral Rehabil 2004;31, 900-4.

11. Hammad IA. Intrarater repeatability of shade selections with two shade guides. J. Prosthet Dent 2003; 89:50-3.

12. McMaugh DR. A Comparative analysis of the colour matching ability of dentists, dental students, and ceramic technicians. Aust Dent J 1977;22:165-7.

13. Davidson SP, Mylinski NR. Shade selection by color vision defective dental personnel. J Prosthet Dent 1990;63:97-101.

14. Barna GJ, Taylor JW, King GE, Pelleu GB. (1981). The influence of selected light intesities on color perception within the color range of natural teeth. J Prosthet Dent 1981;46:450-3.

15. Özdoğan MS, Özdoğan S, Yılmaz C, Hasanreisoğlu $B$, Akçabay C. Dişhekimliği Lisans öğrencileri ve protetik diş tedavisi anabilim dalı lisansüstü öğrencilerinin farnsvvorth-munsel 100 hue testi ile renk tonu algılama yeteneklerinin karşılaştırılması. GÜ Diş Hek Fak Derg 2006;23:91-5.

16. Douglas RD, Przbylska M.Predicting porcelainthickness required for dental shade matches. J Prosthet Dent 1999;82:143-9.

17. Hasselton DR, Diaz-Arnold AM, Dawson DV. (2005). Color stability of provisional crown and fixed partial denture resins. J. Prosthet Dent 2005;93:70-5.

18. Li Y. Tooth color measuremnent using chromometer techniques, advantages and disadvantages. J Esthet Restor Dent 2003;15 Suppl 1(5):33-41.

19. Lath DL, Wildgoose DG, Guan H, Liley TH, Simith RN, Brook AH. J Clin Dent 2006;17:10-3.

\section{Yazışma Adresi:}

Doç. Dr. Şebnem. BEGÜM TÜRKER

Marmara Üniversitesi

Diş Hekimliği Fakültesi

34365 Nişantaşı İstanbul,Türkiye

Tel: 02122319120 (301)

Fax: 02122465247

e-mail: begumturker @ hotmail.com 